\title{
Total Quality Management (TQM) Practices of School Administrators in Relation to School Performance among Teacher Education Institutions in the Province of Quezon
}

\section{Lourdes B. Avila}

Polytechnic University of the Philippines, Lopez (Branch), Quezon

\section{Abstract}

One of the emerging philosophies of management is that of total quality management. Total quality management has received wide acclaim enhancement in industry as well as school nowadays. School started to explore the potential for applying the

Corresponding Author: Lourdes B. Avila

lourdes.avila92@yahoo.com

Received: 23 April 2018

Accepted: 8 May 2018

Published: 4 June 2018

Publishing services provided by Knowledge

(c) Lourdes B. Avila. This article is distributed under the terms of the Creative Commons

Attribution License, which permits unrestricted use and redistribution provided that the original author and source are credited.

Selection and Peer-review under the responsibility of the IRCHE 2017 Conference Committee.

\section{G OPEN ACCESS} TQM philosophy to education, this requires the number of changes in any educational institution particularly in the attitudes and activities of the leadership and educators, in the organization, monitoring of educational process, in the evaluation of the result, in the culture of communication, in the school atmosphere and especially in the area of interpersonal relations.

The School administrators being the highest-ranking official in the school are responsible for the overall operation of a school, and in the $21^{\text {st }}$ century the school administrator wear a multiple of hats just to make sure that the operation in the school goes smoothly, meaning the effectiveness with which he/she handle the tasks assigned to him being the growing interest in improving the efficiency and relevance of these activities is reflected in the adaption of total quality management mechanism, through the institutional actions towards the development of a quality culture, these embedding the philosophy of centennial improvement or the processes of institutional modernization, search for critical factors and clarification of mission and objectives which will eventually lead to quality improvement.

The study assessed the total quality management practices of school administrators in terms of curriculum and instruction, human resources, physical facilities, budget allocation and research in selected teacher educational institutions in the Province of Quezon in relation to school performance for the first semester of SY: 2016-2017. The respondents included 132 teachers and 37 school administrators for eight Teacher Education Program in the Province of Quezon both private and public colleges/universities. Included in the assessment are the status of the school performance in terms of faculty performance, enrollment rate, dropped-out rate, 
retention rate and graduation rate and the awards and recognitions received by the respondent schools. The research on the Total Quality Management Practices hoped to bring improvement in the quality of education for the respondent schools and could also provide information on how this could be done by school administrators in the operation of the school, the students on the other hand maybe guided by the skills of the school administrators that may affect their academic performance.

The study was anchored with Deming's theory of Total Quality management, where it was believed to provide quality body of methodologies that are customer-based and service oriented. As mentioned the study assessed the total quality management practices of school administrators in selected teacher educational institutions in the Province of Quezon in relation to school's performance and eventually to find out if there is a significant relationship between the assessment of TQM practices of the school administrators and performance of the school and at the end developed an action plan just to enhance the TQM practices to improve the school performance.

The study used the descriptive research for this is the precise research design applicable to be used, this study described the total quality management practices of school administrators in selected teacher educational institutions in the Province of Quezon in relation to the students' academic Performance. As told by Calderon, descriptive research is the process of gathering, analyzing, classifying and tabulating data about prevailing conditions, practices, beliefs, processes, trends and cause-effect relationship and eventually making adequate interpretation of such data. This process fits the Kind of research undertaken by this study. The purposive sampling technique was used for the selection of the respondents (teachers and school administrators). The researcher prepared a questionnaires which was used in gathering data and this was validated by experts in the field of educational leadership and with enough experiences in leadership and management practices of the different educational programs in the tertiary level. The researcher personally disseminated the questionnaire to the respondents, and after answering personally retrieved then, an unstructured interview was also conducted both to the school administrators and teacher respondents to elicit some information and answers which were not clearly expounded from the questionnaire. These data obtained were collected, tabulated, analyzed and interpreted using some stalestical tools.

Keywords: School Administrators, Performance, Strategic Direction 


\section{Introduction}

One of the emerging philosophies of management is that of total quality management. TQM has received wide acclaim as an effective approach for achieving quality and performance enhancements in industry. With its recognition and acceptance increasing by the day in the private sector, academic institutions have started to explore the potential for applying the TQM philosophy to education.

TQM approach in education involves not only achieving high quality but also influencing all segments of the educational process: organization, management, interpersonal relations, material and human resources, etc. Applying the approach described above, quality becomes total (integral).

The introduction of total quality management requires a number of changes in educational institutions. The first changes have to occur in the attitudes and activities of the management and educators, in the organization and monitoring of the educational process, in the evaluation of its results, in the culture of communication, in the school atmosphere, and especially in the area of interpersonal relations.

The school administrator is the highest-ranking official in an elementary, secondary, or high school and even in the tertiary level. The school administrators typically report directly to the school president. The school administrators are responsible for the overall operation of a school and is often called school leaders. In an era of shared decision-making and site-based management, the term school leader may also be used in reference to other school administrators and leaders within the school such as assistant principals, lead teachers, and others who participate in school leadership activities.(1)

The job description detailing the responsibilities of the school administrators today bears little to resemblance to that of earlier generations. The twenty-first century school administrators wears a multitude of hats throughout the average school day. While he may begin his day in the office as a disciplinarian, he may go on to perform accounting, custodial, instructional, and nursing duties before returning to his office where a mountain of paperwork awaits him. Regardless of everyone's differing opinions of him as a leader, the primary focus of the school administrator isn't the tasks that he faces daily, but rather the effectiveness with which he handles these tasks. (9) 


\section{Objectives of the Study}

The basic objective of the school is to meet the educational needs of the students as well as the different stakeholders. As the top management leader, the school administrators are obliged to meet such requirements. The school administrators being an education leader are the person whom collaborates with the teacher and the parents, meet distinct requirements and expectations of the customers and direct the resources of the society to the school. The education leader fulfills this function by affecting its surroundings. The education leaders must have knowledge about topics not only as the laws, regulations, management processes and applications concerning the school but also on topics such as the content of the curriculum, program assessment and development. Because, the school administrators as the education leader is the most significant element having impact on the occupational qualification of the teachers at the school, the level of student achievement and the degree of effectiveness at the school functions.

The researcher has observed that there are administrators who are challenged to create an organizational climate, structures and practices for academic success of all students. An administration in a school with a high percentage of learners and a campus considered academically low-performing may be especially challenged to create a total quality management practices.

As a school administrator, he should be familiar with the school setting focusing on curriculum, instruction, human resources, physical facilities, budget allocation, and research. The school has a turbulent past, has had a reshuffling of staff, and needs a new beginning for students who expect educational equity and excellence and a fair chance to graduate from school. The school administrators are expected to employ innovative school reform initiatives adapted to address learners. School administrators are faced with the critical task of achieving equity-based educational excellence and a challenge to balance instruction that prepares all students.

These are the reasons why the researcher prompted to conduct a study on the total quality management practices (TQM) of school administrators in selected higher educational institutions in the Province of Quezon province in relation to schools' performance. 


\section{Method of Study}

This Research deals with the presentation of the research method used by the researcher, the respondents of the study, research instrument of the study, datagathering procedure, validation of data, and the statistical treatment of data.

\section{Design}

This study used the Descriptive Type of Research as this is the precise research design study focusing on the total quality management (TQM) practices of school administrators among teacher educational institutions in the Province of Quezon. The descriptive research fits this study since this study described the total quality management practices (TQM) of school administrators in selected teacher educational institutions in the Province of Quezon. The study described the situation and events more accurately and precisely regarding the total quality management practices (TQM) of school administrators.

As told by Calderon and Gonzales descriptive research is a process of gathering, analyzing, classifying and tabulating data about prevailing conditions, practices, beliefs, processes, trends, and cause-effect relationships and then making adequate interpretation of such data.

Sampling Technique. This was used for the selection of faculty and administrator's respondents in this study. As stated by Pagoso purposive sampling, also known as selective or subjective sampling, is a type of non-probability sampling technique. Nonprobability sampling focuses on sampling techniques where the units that are investigated are based on the judgment of the researcher. In this study the administrators are selected since they are the ones who oversee the system of the university. The respondents were those teachers and administrators in the selected teacher educational institution in the Province of Quezon. The administrators included the president, and the vice-presidents. The teachers were selected based on the selection criteria that they have been in the school for 5 years.

Sampling Size. The respondents of the study came from teacher educational institutions in the Province of Quezon during the first semester school year 2016 - 2017. The respondents included 132 teachers, and 37 school administrators including OIC and Assistant to the administrators. 


\section{Instrumentation}

The researcher prepared a questionnaire which was used in data gathering. To gather the needed data, the researcher utilized the following instruments:

Questionnaire. For data gathering purposes, the researcher used a set of questionnaire that elicited the respondents' assessment on the total quality management (TQM) practices in terms of curriculum, instruction, human resources, physical facilities, budget allocation, and research.

In constructing the questionnaire, the researcher was guided by the ideas that were drawn from literature and studies. The concepts and theories from the literature and studies were utilized as a guide in the formulation of the questions to evaluate the school administrators' total quality management (TQM) practices.

A four-point Likert scale was used to interpret the respondent's answers following the verbal interpretation below:

TABLE 1

\begin{tabular}{|l|c|c|}
\hline Scale & Verbal Interpretation & Scale \\
\hline 4 & Fully Practiced & $3.50-4.00$ \\
\hline 3 & Practiced & $2.50-3.49$ \\
\hline 2 & Moderately Practiced & $1.50-2.49$ \\
\hline 1 & Not Practiced & $1.00-1.49$ \\
\hline
\end{tabular}

Document Analysis was used to analyze the records of the schools' performance pertaining to faculty performance, enrollment rate, dropped-out rate, retention rate, graduation rate and awards/recognition received. Records was identified by the researcher from the different offices of the selected teacher educational institutions in the Province of Quezon.

Unstructured Interview. This was conducted to supplement the answers which was not clearly expounded in the questionnaire.

Validity. The initial content validation were done by three experts in the field of education particularly those who have enough experiences in management practices of the different educational programs in the tertiary level.

Reliability. In order to test the reliability of the questionnaire, that is, the degree to which the questionnaire produces stable and consistent results, the researcher used the test-retest reliability? The test-retest reliability is a measure of reliability obtained by administering the same questionnaire twice over a period of time to a group of individuals. Test-retest reliability is a measure of reliability obtained by administering 
the same test twice over a period of time to a group of individuals. The scores from Time 1 and Time 2 can be correlated in order to evaluate the test for stability over time.

\section{Procedure}

Questionnaire Administration. The researcher initially prepared a draft of the questionnaire based on the statement of the problem posed in Chapter 1. A letter of approval was sought to the school administrator to disseminate the questionnaire. All the approved, questionnaires were disseminated to the school administrators and the teachers personally by the researcher.

Data Gathering. The researcher disseminated the questionnaire to the respondents. The researcher explained the objectives of the study and get the written letter address to the school administrators of each of the selected teacher educational institutions in the Province of Quezon to administer the questionnaire. Questionnaires was administered personally to assure greater percent of retrieval and for explanation of items to the respondents for reliable and complete filling of the items of the said instrument. After answering the questionnaire, the researcher got the questionnaire after filling up the necessary information. An unstructured interview was also conducted both to the administrators and the teachers to elicit some information and answers which were not clearly expounded from the questionnaire.

Data Processing. The data obtained from the questionnaire and interview guides were collected, tabulated, analyzed and interpreted by the researcher. The data collected amazed using appropriate statistical tools.

Data Analysis. The following statistical tools was used in the analysis and interpretation of responses:

1. Percentage was used to describe the schools' performance in terms of faculty performance, enrollment rate, dropped-out rate, retention rate, graduation rate and awards/recognition received. Pagoso defined the percentage formula by; $P=\frac{f}{N} \times 100$

Where: $\mathrm{P}$ - Percentage

$\mathrm{N}$ - Total number of sample

2. Weighted Mean was used to assess the school administrators and teachers' assessment on the total quality management (TQM) practices in terms of curriculum, instruction, human resources, physical facilities, budget allocation, and research. Pagoso obtained the formula by; 
$W m=f w / N$

where: Wm - weighted mean

Fw - frequency $x$ by the weight

$\mathrm{N}$ - total number of respondents

3. z - test was used to determine the significant difference between the school administrators and teachers in the assessment of the TQM practices of the school administrators in terms of curriculum, instruction, human resources, physical facilities, budget allocation, and research.

The formula used was:

$$
\begin{gathered}
Z=\frac{X 1-X 2}{\frac{\int_{1}^{2}}{n 1}+\frac{\int_{2}^{2}}{n 2}}
\end{gathered}
$$

Where:

$\overline{x_{1}}$ - the mean score of the administrators

$\overline{x_{2}}$ - the mean score of teachers

$n_{1}$ - the number of administrators

$n_{2}$ - the number of $r$ teachers

$\mathrm{S}_{1}$ - standard deviation of the administrators

$\mathrm{S}_{2}$ - standard deviation of the teachers

4. Spearman Rank-Order Correlation Coefficient. This was used to measure the association between two variables measured in at least an ordinal scale, wherein the objects or individuals under study are ranked in two ordered series. Spearman's r was used to determine the significant relationship between the TQM practices of the school administrators and performance of the school.

The formula was:

$$
r_{s}=\frac{\sum x^{2}+\sum y^{2}-\sum d^{2}}{2 \sqrt{\sum x^{2} \sum y^{2}}}
$$

where: $\mathrm{x}$ and $\mathrm{y}$ - are the original scores in the variables $\mathrm{x}$ and $\mathrm{y}$

$\mathrm{N}$ - number of respondents

$\sum \mathrm{x}$ - summation of rank of TQM practices

$\sum \mathrm{y}$ - summation of rank of school performance

$\sum x y$ - summation of the product of first and second variable 
5. t-statistic was used to test the significance of Spearman's r. Reyes defined tstatistic by the formula;

$$
\sqrt{t=r \frac{n-2}{1-n^{2}}}
$$

Where:

$\mathrm{t}$ - computed t-value

r - Spearman's r coefficient

$\mathrm{n}$ - number of paired observations

All statistical computations were guided with the use of the Statistical Software package SPSS version 17

\section{Results and Discusssions}

The following are the major findings of the study arranged according to specific problems:

1. What is the assessment of the teachers and school administrators themselves on the school administrators total quality management (TQM) practices in terms of curriculum, instruction, human resources, physical facilities, budget allocation and research?

1.1. As a whole, the schools administrators were rated by themselves as having practiced total quality management (TQM) as shown by the grand weighted mean of 3.49. They fully practiced TQM in instruction and human resources but practiced only all the other components of TQM with the area of research receiving the lowest weighted mean of 3.35 .

1.2. One private school and two public schools were found to have administrators that fully practiced TQM since the average weighted means reached the range of $3.50-4.49$. The rest of the school administrators had only practiced TQM as assessed by the administrators themselves.

1.3. According to the teachers, the school administrators had just practiced TQM based from the grand weighted mean of 3.24 with all the areas being assessed as practiced.

1.4. The teachers gave the lowest ratings of 3.10 and 3.19 in the areas of research and budget allocation respectively. 
2. Is there a significant difference between the school administrators and teachers in the assessment of the TQM practices of the school administrators in terms of the aforementioned variables?

2.1. Since all the computed $t$ values are lower than their corresponding tabular values, then at 0.05 level no significant difference was noted between the assessments of the teachers and the administrators on the latters' total quality management practices making the null hypothesis to be accepted.

3. What is the Status of the school in terms of the following performance indicators; enrollment rate, dropped-out rate, retention rate and graduation rate?

3.1. The lowest enrollment rate in the 8 schools was 33 percent while school $C$ (private school) had an enrollment rate of 100 percent.

3.2. Two schools (one public and one private school) had the lowest drop-out rate of 4 percent while school $G$ (public school) had the highest drop-out rate of 13 percent.

3.3. As to retention rate, two schools (one public and one private school) registered the highest retention rate of 96 percent while school D (a private school) had the lowest retention rate of 67 percent.

3.4. Regarding graduation rate, two private schools had one hundred percent graduation rate while one private and one public school had the lowest graduation rate of 83 percent and 84 percent respectively.

4. Is there a significant relationship between the TQM practices of the school administrators and school performance?

4.1. It was found out that TQM practices had negative significant relationship with drop-out rate making the null hypothesis to be rejected.

4.2. TQM practices were found to have no significant relationship with enrollment rate, retention rate and graduation rate leading to the acceptance of the null hypothesis.

5. What strategic direction can be developed to enhance the TQM practices of the school administrators to improve the school performance?

A strategic direction/initiative based from the findings was prepared by the researcher with the hope of enhancing the TQM practices of the school administrators that will consequently improve the school performance. (Please refer to Strategic Direction for Teacher Education Institution in the Province of Quezon. Leadership Initiative to Re-Invent Education in the $21^{\text {st }}$ (entury) 


\section{Conclusion and Recommendation}

In the light of the findings, the following conclusions were drawn:

The school administrators are moderately practicing total quality management according to the two groups of respondents.

The administrators are not very much adept with total quality management when applied in the areas of research and budget allocation.

The teachers and school administrators have the same view regarding the practice of total quality management of school administrators.

Public schools and private schools have varying performance in school performance indicators.

Total quality management practices of school administrators affect negatively dropout rate but have no direct relationship with enrollment rate, retention rate and graduation rate.

Based from the findings and conclusions of the study, the following recommendations are hereby offered:

School administrators should enhance their skills in practicing total quality management especially in the areas of research and budget allocation which is addressed in the proposed action plan.

School administrators should take the opportunity to attend trainings on total quality management for them to apply it in their work.

The proposed strategic direction may be adapted by the school administrators to see its functionality and contribution in enhancing their TQM skills and be evaluated periodically for further refinement.

A similar study maybe conducted utilizing bigger research venue and more respondents.

\section{Author's Note}

Lourdes B. Avila

Asso. Professor

Polytechnic University of the Philippines

Lopez (Branch), Quezon

lourdes.ovila92@yahoo.com 


\section{References}

[1] Andrada, L. M. (2008). Making Curriculum Innovations Work for your School. A position paper presented at the second PAVEA National Congress. Dauis, Bohol.

[2] Bennell, P. (2007). Promoting Livelihood Opportunities For Rural Youth, Paper presented at Roundtable 3: Generating remunerative livelihood opportunities for rural youth. : IFAD Governing Council.

[3] Brewer, H. (2001). Ten steps to success. Journal of Staff Development,

[4] Buffie, E. G. (1989). The principal and leadership (Elementary Principal Series No. 1). Paper presented at the Annual Meeting of the American. Educational Research Association, Bloomington, IN. (ERIC Document Reproduction Service No. ED 315911,

[5] Cangas, R. H. (2008). Technical Vocational Education: Then and Now. A position paper presented at the second PAVEA. : National Congress.

[6] Fowers, B. J. 2008 from Continence to Virtue: Recovering Goodness, Character Unity, and Character Types for Positive Psychology. : Theory. : Psychology.

[7] Hean, R. (2004). Understanding Student Teacher Interaction First PAVEA. National Congress, Laog City,

[8] Labrador, V. L. (2004). Learning the R's In The Classroom And The Basic Skill for Employment. Second PAvea National Congress, Laog City,

[9] Nakpodia, E. D. (2006). Current Issues in Nigerian Educational System. Edited by PO Itedjere. : Abraka, Delsu Publishers.

[10] Palmer, R. (2007). Skills for work?: From skills development to decent livelihoods in Ghana's rural informal economy. International Journal of Educational Development, 27(4), 397-420. Retrieved from http://linkinghub.elsevier.com/retrieve/pii/ So738059306001222 doi:10.1016/j.ijedudev.2006.10.003

[11] Pontillan, P. C. 2002 in Fusing Productivity and Quality Seminar Workshop and Total Quality Management. Argao Cebu.

[12] Management, S. Training Program for Vocational School Administrators, 2009 Asianlnstitute of Development Studies. : Davao City. 